\title{
CONSTRUCCÍON DE LA MATRIZ NEOLIBERAL EN EL DISCURSO PÚBLICO: ESTRATEGIAS DE SEMIOTIZACIÓN
}

(Construction of the neoliberal matrix in public discourse: semiotization strategies)

\author{
Neyla Graciela Pardo Abril ${ }^{1}$ \\ (Universidad Nacional de Colombia - UNC) \\ Juan Ruiz Celis ${ }^{2}$ \\ (Universidad Nacional de Colombia - UNC)
}

\begin{abstract}
Seen from the perspective of critical discourse studies, this paper analyzes the Colombian President Juan Manuel Santos' inaugural speech, performed on August 7, 2014, which was broadcast by various media. Different categories from semiotics, sociology and political science are used in order to account for the forms of semiotization through which the representational systems underlying the neoliberal regime are stabilized in political discourse. Thematic units and contextual designs are analyzed through temporal markers, nominalizations, narrative instantiations, repetitions, attributions, among other semiotic-discursive categories.
\end{abstract}

Keywords: Speech, neoliberalism, semiotic resource, discursive strategy, emotionality.

\section{RESUMEN}

Se analiza el discurso de posesión del presidente colombiano Juan Manuel Santos del 7 de agosto de 2014, desde la perspectiva de los estudios críticos del discurso, el cual fue difundido por distintos medios de comunicación. Se apropian categorías de los campos de la semiótica, la sociología y la ciencia política, para dar cuenta de las formas de semiotización a través de las cuales son estabilizados en el discurso político, los sistemas representacionales que fundamentan el régimen neoliberal. Se analizan unidades temáticas, diseños contextuales a través de marcadores temporales, formas de nominación, ejemplarización narrativa, reiteración, atribuciones, entre otras categorías semiótico-discursivas.

Palabras clave: Discurso, neoliberalismo, recurso semiótico, estrategia discursiva, emocionalidad.

\footnotetext{
${ }^{1}$ Doctora en Filología-Lingüística Española. Profesora titular e investigadora del Instituto de Estudios en Comunicación y Cultura (IECO) y del Departamento de Linguística de la Universidad Nacional de Colombia. Investigadora principal del Grupo Colombiano de Análisis del Discurso Mediático (COLCIENCIAS), cofundadora de la Red Latinoamericana de Analistas del Discurso sobre la Pobreza (REDLAD) y presidente de la Federación Latinoamericana de Semiótica (FELS).

${ }^{2}$ Politólogo de la Universidad Nacional de Colombia y magister en Políticas Sociales de la Universidad de Buenos Aires. Miembro del Grupo Colombiano de Análisis de Discurso Mediático (COLCIENCIAS), coordinador de la línea de investigación "Discurso, Identidad, Memoria y Desposesión" de la Red Latinoamericana de Analistas del Discurso sobre la Pobreza (REDLAD Colombia). Integrante del movimiento de Hijos e Hijas por la Memoria y Contra la Impunidad.
} 


\section{Introducción}

La emergencia de procesos económicos a gran escala, en el marco de los cuales se han desarrollado las actuales crisis de los distintos modelos de acumulación, ha conducido a la trasposición de los sistemas sígnicos que fundamentan las relaciones económicas, a todos los ámbitos de la vida social. Esta ampliación de la esfera de influencia de lo mercantil ha conllevado a la traslación del discurso del miedo a la pobreza, del déficit público, de la necesidad de inversión, de la lucha contra la inflación, etc., a entornos político-culturales más amplios. Este fenómeno cobra mayor relevancia mientras más difíciles son las condiciones de recesión en los distintos países. En el caso de las llamadas “economías emergentes" el discurso económico ha impulsado directrices de acción basadas en ideales como la inversión extranjera, la eliminación los Estados de bienestar -que nunca lograron su pleno desarrollo - y la individualización de la responsabilidad sobre los riesgos sociales, con lo que esto implica en términos de la eliminación gradual del acceso a los derechos de ciudadanía social.

El caso colombiano cobra valor en tanto permite identificar la tendencia general latinoamericana de la supresión de los derechos sociales, con las particularidades asociadas al desarrollo del conflicto armado interno, en cuya base se encuentra una vieja disputa entre distintos actores sociales en torno a las formas de distribución de la riqueza. En tanto permite evidenciar los ejes sobre los que se construye lo público, el discurso político mediatizado se propone como el núcleo de esta reflexión, con el fin de evidenciar las prácticas de semiotización desde las que se estabiliza el modelo neoliberal, actualmente en boga en varios países de América Latina. Se aborda el uso de representaciones del entorno económico en los diferentes ámbitos de la vida social y sus potenciales efectos sobre la estabilización de una 'semiótica del poder'.

Se analiza el discurso de posesión del presidente colombiano Juan Manuel Santos del 7 de agosto de 2014, que fue difundido por distintos medios de comunicación. Se apropian categorías de los campos de los estudios críticos del discurso, la semiótica, la sociología y la ciencia política, para dar cuenta de las formas de semiotización a través de las cuales son estabilizados en el discurso político, los sistemas representacionales que fundamentan el régimen neoliberal. 


\section{Producción y estabilización de universos semióticos}

La complejidad de los escenarios de la comunicación contemporáneos, en razón de los cambiantes espacios de circulación de la información, ha venido acentuándose mientras más emergen distintos tipos de dispositivos de producción representacional. Los lugares de construcción de los asuntos públicos, otrora garantizados por el Estado y caracterizados por la fuerte regulación institucional, han venido mutando en respuesta a la entrada en escena de actores no estatales de cuya correlación han surgido nuevos referentes que se han impuesto como horizontes de sentido. Las dinámicas del capitalismo tardío y el repertorio de objetos semióticos a través de los cuales ha transferido sus marcos axiológicos a los distintos espacios de la vida social se han multiplicado ante la diversidad de formas discursivas actuales. Esto ha sido especialmente relevante en el discurso político, el cual ha apropiado categorías económicas como algunas de sus herramientas de persuasión y de modulación de las subjetividades políticas.

Las reflexiones sobre el capitalismo desde la teoría social contemporánea han descentrado la reflexión sobre su funcionamiento, de los dispositivos de producción y reproducción de la vida material (Bourdieu, 2012; Foucault, 2012; Deleuze y Guattari, 2012; 2013; Bauman, 2009). Las formas de construcción de sentido han adquirido relevancia en las reflexiones actuales toda vez que permiten identificar los procesos de subjetivación y los horizontes representacionales desde los que es posible interpretar las prácticas sociales en los niveles individual y colectivo. La relación que se establece entre sujeto, poder y saber, a través de la acción discursiva, ha permitido identificar las formas como los procesos de acumulación se han desarrollado al amparo de formas de entender y asumir la realidad, en el marco de las cuales la axiología capitalista se ve refrendada como patrón de inteligibilidad y como referente de orientación conductual.

El capitalismo y los procesos sociales que le son inherentes pueden ser interpretados a partir de la identificación de los regímenes semióticos desde los que estructuran las distintas formas de producción de sentido y las relaciones de poder que les corresponden. Los procesos de simbolización de lo material se constituyen en referentes de modificación de la materialidad misma de los objetos y procesos del mundo físico y social, desde los cuales se refrendan intereses, se generan lógicas sistémicas y se las intenta preservar en el tiempo. Estos procesos, de acuerdo con Deleuze y Guattari $(2012,119)$, conducen a la creciente abstracción del universo semiótico, en la que las referencias sígnicas van de una a otra, construyendo un 
continuum de cadenas referenciales de cuyas intersecciones se deriva "todo un régimen de enunciados flotantes, errantes, de nombres suspendidos, de signos que acechan, que esperan ser empujados por la cadena para volver [...] El régimen significante no solo tiene como tarea organizar en círculos los signos emitidos desde todas partes, sino que continuamente debe asegurar la expansión de los círculos o de la espiral [...]”"

El planteamiento de Deleuze y Guattari $(2012 ; 2013)$ hace énfasis en tres elementos cuya junción permite explicar y comprender algunos de los rasgos del capitalismo contemporáneo y la forma como los centros de significación económicos se organizan de acuerdo a dinámicas de expansión semiótica: la elaboración de regímenes significantes, la producción industrial de mecanismos de interpretación y la modulación de las subjetividades. En la base de esta expansión se encuentra la refrendación de los procesos de abstracción y de las dinámicas de poder que corresponden a los regímenes de significación, y que habilitan las prácticas de acumulación constitutivas del capital. El capitalismo puede entenderse como la intersección dinámica de distintos sistemas de semiotización orientados a la extracción de valor y al acrecentamiento de los procesos de acumulación de capital, dentro de los cuales el capital económico es solo uno de sus ejes. Una de las formas de afirmación del capitalismo corresponde con la puesta en escena de distintos dispositivos de percepción.

El análisis del capitalismo es cualificado si se ponen en relación los componentes semióticos de los sistemas capitalistas y los lazos de socialización que dichos componentes producen a través de la modulación de la percepción, la formación de instituciones, la definición de espacios de acción y la producción de dispositivos de regulación. De acuerdo con Guattari (2013, 23), el capitalismo se sostiene en virtud de la sobrecodifición de los distintos componentes semióticos de acuerdo a los centros de significación sobre los que los procesos capitalistas validan su reproducción. Esta sobrecodificación supone la jerarquización y el ordenamiento de las formas de inteligibilidad social de acuerdo a grillas semióticas "que funcionan fundamentalmente como máquinas de sujeción al servicio de las formaciones de poder [...] y, secundariamente, como modelo de expresión significativo”.

Las potencialidades del análisis semiótico para explicar las dinámicas del capitalismo contemporáneo también toman como eje los nexos entre los procesos de poder que se llevan a cabo en los niveles macro de la vida social, y las micropolíticas de producción de la libido social, cuya operacionalización define la elaboración sistemática de ciertas formas de afectividad, que toman como base la experiencia sensible de los sujetos. La producción de la 
libido social se explica en relación a los flujos de significado y su potencial efecto sobre los procesos de percepción y de activación de emocionalidades y deseos, desde las que se incentivan formas de ser y hacer en conexión con los procesos de territorialización del capitalismo, en los escenarios microsociales. En consecuencia, el funcionamiento de los componentes semióticos se constituye en la condición de posibilidad de la infraestructura económica capitalista, en tanto la característica central del capitalismo globalizado en su etapa neoliberal consiste en la focalización de su injerencia sobre el campo de las representaciones sociales, con el propósito de expandir su radio de influencia a todos los espacios de la vida social (Leghissa, 2012).

Reflexiones recientes sobre el neoliberalismo han tomado como punto de referencia la dimensión cognitivo-representacional y los procesos de poder inherentes a la gestión de la psiquis. Klein (2011) ha problematizado las formas como, desde las consignas de Friedman (2008), se han sugerido directrices para la implementación de la denominada 'doctrina del shock', la cual tiene como fundamento dos formas de intervención sobre la acción social: por una parte, la generación de crisis que sean percibidas como tales para desestructurar las formas estabilizadas de representación y de acción sobre la realidad. Por otra parte, la acción rápida y estratégica por parte de los grupos de poder para asegurar los cambios necesarios que buscan profundizar las dinámicas del régimen de acumulación.

Uno de los aspectos centrales de la discusión sobre el capitalismo neoliberal es la forma como desde los centros de poder se producen formas de percepción y de compresión de la realidad, de manera que sea más fácil la expansión de las políticas neoliberales a través de la conmoción y la movilización emocional. Emociones como el miedo, la conmoción, el terror y demás estados psíquicos de parálisis cognitiva constituyen catalizadores del neoliberalismo, que se ajustan a lo que se ha denominado el 'complejo del capitalismo del desastre'. La construcción de un engranaje del desastre funciona como una infraestructura que se orienta a la transformación de la voluntad de los sujetos, aprovechando los estados psíquicos que se sustraen al postrauma y que contribuyen a la renuncia de valores que en otras circunstancias contribuirían al ejercicio de la resistencia: "en esos momentos maleables, cuando no tenemos un norte psicológico [...], los artistas de lo real sumergen sus manos en la materia dócil y dan principio a su labor de remodelación del mundo" (KLEIN, 2011: 46).

La comprensión de la forma como se orientan semióticamente las emociones y las relaciones entre dichas emociones, las creencias y las acciones de los agentes sociales 
permiten dar cuenta del funcionamiento del poder, especialmente en los discursos que se hibridan con modalidades de intervención políticas. El discurso político adquiere relevancia en tanto sintetiza relaciones de poder, a través del uso de recursos semióticos que, al ser utilizados de manera estratégica, orientan los procesos de interpretación, modulando así las posibles prácticas que se derivan del uso de la información. La acción discursiva puede entenderse como la puesta en escena de distintos tipos de prácticas semióticas en las que se combinan recursos y estrategias en la construcción de significado, y en la que se movilizan formas de saber-poder (PARDO ABRIL, 2014).

El discurso político puede ser definido como una modalidad semiótico-comunicativa, que, mientras relata acontecimientos de interés colectivo, se orienta a disuadir, convencer y a definir relaciones entre sujetos individuales y colectivos, tomando como punto de referencia los procesos en el marco de los cuales se ejerce poder, con el fin de legitimar intervenciones sobre los escenarios públicos. El poder, para efectos del análisis del funcionamiento de los objetos semiótico-discursivos, puede ser entendido como un conjunto de acciones de significación a través de las cuales se define la existencia representacional de los agentes que son referenciados en el discurso, y como un conjunto de acciones que producen y orientan las representaciones y las acciones de quienes tienen acceso a dicho discurso.

El discurso político se caracteriza por movilizar los sentidos asociados con la afectividad y las categorías de pertenencia, con las cuales se aspira a elaborar la percepción de identidad y solidaridad. De acuerdo con Reicher y Hopkins (2001), la escenificación del rol del líder pasa por establecer contacto con sus interlocutores a través de recursos discursivos como el uso de nominales colectivos de pertenencia, que refuerzan referentes de identidad nacional para construir la percepción de integración étnica, social y política. El carácter político del discurso se deriva de la potencialidad que tiene para generar condiciones sígnicas capaces de movilizar adhesiones. Por consiguiente, remite a la eficacia simbólica en la concreción de estrategias de persuasión, las cuales se encuentran en conexión con los entornos sociales de los que emerge la actividad discursiva.

En el discurso político las relaciones de poder y saber se entretejen con el propósito de modular las expectativas de los interlocutores mediante las cuales, por una parte, se refuerzan los lugares agenciales de los sujetos cuya intervención es legitimada y jerarquizada, y, por otra, se despoja a una parte de la sociedad de gestionar sus propios asuntos. A través de distintos marcadores semióticos, el discurso político construye un usuario imaginado, al cual 
se le atribuyen roles, lugares y capacidades agenciales, y al cual se le sugiere la ruta de interpretación que se deriva de la interpelación política. El discurso define una estructura modal que estimula a los interlocutores a la aceptación de determinadas posiciones, a través de estrategias semióticas que se orientan a la producción de isotopías, en las que se activan formas de refrendación de obligaciones y deberes que se proyectan sobre el plano de lo fáctico (FABBRI Y MARCARINO, 2011).

\section{Ruta metodológica}

La promesa y búsqueda de una teoría y de propuestas analíticas para la exploración de los discursos mediáticos es una preocupación constante en la investigación interdisciplinaria. Este trabajo integra métodos cualitativos y cuantitativos en la búsqueda por generar explicaciones que permitan poner en relación los discursos mediáticos, con los escenarios socio-históricos de su producción y circulación. Para el análisis del corpus se apropia la herramienta estadística T-Lab 7.3, la cual permite explorar tendencias e identificar la combinación de fenómenos discursivos relevantes, que favorecen el análisis de las distintas dimensiones semióticas constitutivas del discurso. El proceso analítico incluye el examen de datos, su codificación, la escritura de notas, la elaboración de descripciones, la construcción de categorías y la identificación de las relaciones intra e interdiscursivas.

El uso de T-Lab 7.3 se justifica en razón de la extensión del objeto semiótico que se analiza, el cual corresponde con el discurso de posesión del presidente Juan Manuel Santos, el 7 de agosto de 2014, que fue publicado en la página web de la Presidencia de la República de Colombia. Esta fecha adquiere relevancia en tanto constituye el primer día de un gobierno reelecto, cuya consigna "Todos por un nuevo país. Paz, equidad y educación" define sus ejes de acción en dos perspectivas: por una parte, la implementación del modelo transicional en Colombia y la consecución de la paz con los grupos insurgentes que operan en distintas zonas del país, desde hace más de cincuenta años. Por otra parte, la profundización del modelo económico neoliberal que ya había sido reforzado por el presidente Santos en su primera administración a través de la implementación de políticas focalizadas, una mayor liberalización económica y la captación de la inversión extranjera.

El procedimiento metodológico se elabora en fases que incluyen la identificación del problema social objeto de análisis, su interpretación, el análisis de las configuraciones semiótico-discursivas, las representaciones que se construyen discursivamente y su relación 
con los mecanismos y las estrategias agenciadas a través de los actos comunicativos. En primer lugar, se identifica la desigualdad como problema social derivado de la expansión de las políticas neoliberales, y se aborda el discurso presidencial en una coyuntura que, entre muchos otros sucesos, incluye la continuidad de los diálogos de paz con la insurgencia y la formulación de propuestas para construir una "nueva Colombia", con mayor inclusión y desarrollo. El procesamiento del corpus incluye el empleo de técnicas estadísticas a través TLab 7.3 como el análisis de frecuencias y de correspondencias múltiples, y la identificación de coeficientes de correlación para determinar asociaciones semánticas. T-Lab 7.3 es un software iterativo que permite, a través de un conjunto de herramientas lingüísticas, analizar coocurrencias de unidades léxicas, identificar índices de asociación, elaborar comparaciones entre parejas de unidades léxicas que se pueden ampliar a expresiones y describir secuencias en cotextos, del total de las unidades del corpus y de las concordancias.

En segundo lugar, se describe el corpus y se identifican las categorías y relaciones que tejen el proceso de producción de significado. En este proceso se aspira a generar explicaciones que den cuenta de las relaciones que se establecen entre lo que se propone discursivamente, las representaciones que emergen, las formas de estabilización de dichas representaciones y la construcción de universos de sentido, con efectos sobre las prácticas sociales. Se toman como punto de referencia las unidades léxicas "igualdad", "prosperidad", “derechos", "paz”, “guerra", “equidad”, "beneficio” y "trabajo".

En tercer lugar, se ponen en relación los discursos construidos con las condiciones sociales y políticas de su producción y circulación. Se reconstruyen las formas como quedan representados los conflictos, las maneras como la actividad discursiva involucra aspectos como la identidad, los roles, las normas sociales que habilitan dichos roles, la distribución de recursos simbólicos y los mecanismos a través de los cuales quedan estabilizadas las creencias, los valores y las representaciones que se proponen como referentes cognitivos, orientadores de los procesos de socialización. Se da cuenta de las posibles consecuencias sociopolíticas de los hechos comunicativos, reflexionando sobre las relaciones entre el universo referencial elaborado y las prácticas de poder de distintos actores sociales. 


\section{Breve acercamiento a la realidad socio-histórica colombiana}

Las disputas en torno al modelo de acumulación y al acceso a los recursos simbólicos y materiales disponibles han orientado el devenir histórico colombiano, y han sentado las bases para el desarrollo del conflicto social y armado que persiste en Colombia desde hace 60 años. Las tensiones sociales en razón de las clausuras del sistema político; la tenencia, uso y explotación de la tierra; el conservadurismo de las elites políticas y económicas; las rígidas estructuras de estratificación social y la violencia estructural han sido ampliamente documentados como algunos de los fenómenos que han marcado el desarrollo de la historia colombiana (Romero, 2011; Leal y Dávila, 2010; López, 2010; Pardo Rueda, 2010; Múnera y Rodríguez, 2009). Y se han definido el espectro de los altos niveles de conflictividad social

Siguiendo las reflexiones de Corredor (1992), el desarrollo institucional colombiano, así como las formas de construcción de lo público, han estado marcados por dos procesos que se han llevado a cabo de manera paralela y contradictoria y han minado las posibilidades de integración social y de construcción de un proyecto de país tendiente a la cualificación de lo colectivo. Por una parte, un proyecto de modernización económica liderado por las elites, que ha definido como punto de referencia la adopción del modelo de desarrollo liberal y la consolidación de instituciones típicamente modernas (sistema estatal, instituciones de mercado y partidos políticos). Por otra parte, el arraigo y la reproducción continua de axiologías premodernas que incluyen la refrendación del orden tradicional de hacienda, las relaciones de clientela basadas en criterios de parentesco y lealtad personales, y la adhesión a cacicazgos que obstaculizan el ejercicio democrático. En este sentido, destacan la disputa entre los partidos Liberal y Conservador durante gran parte de la historia colombiana, y la clausura de los espacios de participación de fuerzas políticas y sociales no correspondientes con dichos partidos.

La dinámica de clausura de los espacios de construcción de lo público y el uso de la violencia contra los sectores disidentes por parte de las elites políticas y económicas sentaron las bases para la emergencia de los grupos armados insurgentes, los cuales, desde diferentes corrientes de pensamiento político de izquierda, construyeron discursos y estrategias de acción beligerante frente al dominio de las elites. La acción organizada de las elites en referencia a la práctica colectiva de los partidos Liberal y Conservador contribuyó a la exacerbación de la dinámica centralista y a la consolidación del modelo de desarrollo agenciado por las elites, las cuales, mediante el fomento de la adhesión colectiva a uno u otro 
partido, disiparon el debate sobre el régimen de acumulación en pugnas partidistas en los niveles regional y local. Esta situación, al tiempo que impidió la audibilidad de voces alternativas, reforzó el consenso político de los grupos dominantes (PALACIOS Y SAFFORD, 2006).

La consolidación de los grupos insurgentes y el nacimiento de estructuras paramilitares, apoyadas y financiadas por sectores de la extrema derecha y por los organismos de seguridad del Estado, profundizaron las tensiones en relación con las dinámicas del régimen de acumulación y proporcionaron un ambiente de violencia que resultó propicio para la consolidación de lógicas extractivistas y privatizadoras, particularmente en las décadas de los años ochenta y noventa. Esta situación fue especialmente relevante en las zonas de alta intensidad del conflicto armado, en las cuales los grupos de extrema derecha se constituyeron en garantes de las empresas nacionales y transnacionales, ofreciendo seguridad a los capitales extranjeros, continuamente amenazados por la injerencia de los grupos armados de izquierda, pero alentados institucionalmente a través de la puesta en escena de mecanismos de liberalización económica (LIBREROS Y CARRERO, 2014).

La implementación de políticas neoliberales en el periodo que va del 2000 - 2015 se lleva a cabo en diversas coyunturas que toman como punto de referencia el proceso de desmovilización de los grupos paramilitares confederados en la organización Autodefensas Unidas de Colombia (AUC), los diálogos de paz con las Fuerzas Armadas Revolucionarias de Colombia (FARC), y el establecimiento de acuerdos comerciales con otros países entre los que destacan los tratados de libre comercio con Europa y Estados Unidos. Estos procesos condujeron a la adecuación de la institucionalidad estatal en concordancia con la satisfacción de las demandas del modelo de economía de mercado neoliberal, lo que redundó en la modificación del discurso político e institucional y en la subordinación de los procesos de justicia transicional habilitados por las leyes 975 de 2005 y 1448 de 2011 a la protección del régimen de acumulación. La modificación del discurso político-institucional incluyó la superposición del marco epistémico neoliberal y la progresiva erosión de la lógica de los derechos y cualquier otro marco representacional conducente a la potencialización de lo colectivo.

Los documentos institucionales, desde el punto de vista de la consolidación de la episteme neoliberal, propiciaron transformaciones representacionales en la forma de entender la política y las formas de intervención estatal en los escenarios públicos. Así, 
progresivamente, las prestaciones estatales orientadas a la satisfacción de los estándares de acceso a los derechos ciudadanos fueron conceptualizadas como "beneficios", los sujetos de derechos fueron nominados como "beneficiarios" y los sujetos políticos - aquellos que deberían participar en la definición de los asuntos públicos- fueron desdibujados en su capacidad de agencia y de organización colectiva, al sugerírselos como individuos dispersos depositarios de las "iniciativas" estatales y de la empresa privada. De esta manera, los marcos neoliberales colonizaron los distintos escenarios que otrora correspondían con los espacios de refrendación desde lo institucional de los procesos de construcción comunitaria de la vida social.

\section{Horizonte representacional y consolidación de la matriz neoliberal}

El discurso "Palabras del Presidente Juan Manuel Santos en su posesión para el período presidencial 2014-2018"3 (DP) permite delinear los ejes de lo que serán las estrategias de intervención gubernamentales en el segundo periodo de gobierno de Juan Manuel Santos y da cuenta de los campos de inteligibilidad alrededor de los cuales se diseñarán e implementarán las principales políticas públicas de su administración. Se justifica el abordaje de este discurso no solo por lo que permite inferir en términos de los posibles ámbitos de acción gubernamental, sino por la coyuntura de los diálogos de paz con las Fuerzas Armadas Revolucionarias de Colombia (FARC) y la implementación de los tratados de libre comercio con varios países. Entre los países con los que Colombia ha suscrito tratados de libre comercio se encuentran Estados Unidos, Canadá, México, la Unión Europea, Chile, Corea del Sur, entre otros, lo cual ha implicado la adecuación institucional y de la intervención estatal sobre los distintos territorios, en concordancia con las obligaciones internacionales contraídas por el Estado en materia comercial.

El DP integra los recursos semióticos que se han organizado con el propósito de relatar, en perspectiva institucional, las propuestas de acción gubernamentales como si fuesen iniciativas de interés colectivo, para lo cual hace uso de marcadores de pertenencia social. El DP se propone disuadir, convencer, conmover y definir lineamientos y relaciones entre los todos los miembros de la comunidad, para lo que construye un conjunto de representaciones con consecuencias prácticas en la vida social, que tienen la función de orientar las acciones

\footnotetext{
3 Ver http://wsp.presidencia.gov.co/Prensa/2014/Agosto/Paginas/20140807_03-Palabras-del-Presidente-Santosen-su-posesion-para-el-periodo-presidencial-2014-2018.aspx.
} 
individuales y colectivas, movilizando los sentidos que se pueden derivar de la afectividad, las axiologías que proceden de los idearios políticos que se pretenden estabilizar y la funcionalización del sufrimiento. Se generan interpelaciones en las que el Estado propone atención y empatía hacia algunos grupos históricamente marginalizados. La representación que emerge de este proceso es que los sujetos son beneficiarios de un Estado que actúa en alianza con el sector financiero y privado, como garante de su inversión y como proveedor de las condiciones sociales proclives a la expansión de su mercado.

El DP propone cuatro unidades temáticas que se articulan a la construcción de estrategias discursivas elaboradas a partir la intersección entre las emocionalidades y los valores que consolidan el sistema neoliberal. La primera unidad da cuenta de la representación de la nación; las otras tres unidades constituyen la base programática de las políticas públicas para el segundo periodo de gobierno de Santos: "paz", "equidad" y “educación". Los marcos conceptuales desde los cuales se definen estos ejes toman como base los procesos de fragmentación grupal a través de los cuales discursivamente se ubica a los sujetos políticos en diversas categorías de pertenencia y se refuerza la matriz neoliberal en tres perspectivas: a través de la representación del individuo como sujeto político central; mediante la elaboración del campo semántico de la prosperidad; y por medio de la formulación del marco de la competencia, el cual se propone como principio organizativo de la dinámica social.

Los diseños contextuales que se elaboran en el discurso, a través de la marcación de puntos de ruptura temporales, establecen una diferenciación entre un ayer en el que se ubican los problemas de una Colombia condicionada por su historial de violencias, y un hoy que se representa como punto de inflexión del cambio social: "Es nuestra hora... iy vamos a aprovecharla". Estas marcaciones temporales son uno de los recursos semiótico-discursivos más relevantes y frecuentes en cuyas articulaciones se llevan a cabo estrategias de legitimación que se orientan a la estabilización de los sistemas de valores que sostienen las propuestas de intervención del régimen neoliberal y que perfilan las representaciones que sirven como punto de referencia para la implementación del modelo transicional colombiano.

Los marcadores de temporalidad incluyen los deícticos "hoy", "ahora", "año" y "hora"; el uso de verbos que indican procesos y que se relacionan con haceres prácticos como "seguir", "avanzar", "llegar" y "comenzar"; atributivos con función de legitimación como "nuevo" y "pasado"; y comparativos que indican ruptura como "mejores", los cuales tienen 
función propagandística. Estos recursos semiótico-discursivos buscan enfatizar el sentido de cambio y de transformación, y lograr la diferenciación entre las intervenciones estatales en la administración de Juan Manuel Santos y las administraciones pasadas. A estas últimas, a través de implicaturas o referencias indirectas, se les atribuye un carácter negativo, de carencia de efectividad en sus acciones y de ausencia de gestión sobre los ejes discursivos que se proponen como prioridad:

A diferencia de lo ocurrido en el pasado, en este proceso tiene que haber reparación y se debe esclarecer lo sucedido.

[...] hace cuatro años prometí bajar el índice de desempleo a un solo dígito, y crear 2 millones y medio de empleos. ¿Qué alegría poder decir hoy a mis compatriotas que SUPERAMOS LA META [...]!

[...] Hoy comienza otro mandato, y voy a hacer todo, todo lo que esté a nuestro alcance para que transformemos a Colombia a través de la educación.

[...] Hace cuatro años Colombia tenía dificultades que parecían insalvables con algunos vecinos.

Estos componentes permiten verificar tensiones, reconocer procesos de estabilización cognitiva e identificar sus posibles implicaciones en los distintos ámbitos de la vida social. La construcción temática pone en tensión el estatus ontológico que se deriva de las identidades colectivas propuestas (el Ser social), las obligaciones que en virtud de dicho Ser se deben asumir para hacer parte de la comunidad y los haceres que se derivan de dichas obligaciones. La transitividad representacional que va del Ser al hacer social se concreta en la convocatoria de adhesión a la propuesta gubernamental, sobre los ejes de la identidad grupal:

\begin{tabular}{l}
\hline ES NUESTRA HORA... ¡Y VAMOS A APROVECHARLA! [...] re-pensarnos \\
[...] re-imaginar el contrato social [...] ser más ambiciosos con nuestros sueños
\end{tabular}

Colombia necesita un nuevo pacto social

Es de todos... ¡A Absolutamente TODOS los colombianos!

[...] caminemos JUNTOS [...] trabajemos JUNTOS.

El uso frecuente de nominales colectivos indeterminados sustenta el proceso de legitimación que se formula en el DP, elaborando discursivamente identidades grupales lo 
más abarcadoras posibles, que disipen las disidencias que podrían surgir de las propuestas que se formulan discursivamente: "país", "Colombia", "colombiano", “comunidad", "mundo" y "pueblo". En tanto referentes de consenso y de legitimación, estos recursos contribuyen a validar la agenda de intervención, ya que sintetizan la conexión entre el ser colectivo y el hacer delineado por el DP en torno a asuntos como la paz, la equidad, la educación, el trabajar, el conflicto, la seguridad y la justicia.

En el DP es posible advertir que los agentes más referenciados se relacionan con los sujetos participantes en el desarrollo del conflicto armado: "víctima", "niño", "FARC", "gobierno" y "joven". Es frecuente también la nominación de actores colectivos abstractos como "pueblo", el cual es evocado como recurso de legitimación y como lugar de identidad grupal. Además se evidencia la evocación de la categoría "pobre", la cual es asociada con los procesos históricos de desigualdad en Colombia. Aun cuando se referencian frecuentemente las categorías relativas al conflicto armado, a instancias colectivas abstractas y, en menor medida, a la desigualdad expresada en el fenómeno de la pobreza, los actores directamente involucrados en los procesos de acumulación y de expansión del modelo de mercado no se nombran.

Los empresarios, los inversionistas o incluso quienes sostienen la economía ilegal del narcotráfico son referenciados marginalmente o no son referidos en el discurso. Esto mismo sucede con actores relevantes para la solución del conflicto armado y la consecución de la paz, como los campesinos, los indígenas, los afrocolombianos, los movimientos sociales, las fuerzas militares, la policía, el Ejército de Liberación Nacional (ELN) y los grupos paramilitares. La ausencia de citación, o la baja frecuencia de aparición de estos agentes discursivos permiten inferir la elisión del debate en torno a los procesos de marginalización y segregación que han condicionado el desarrollo del conflicto armado. Esta elisión es un efecto de la estrategia discursiva de atribución de valor a las dimensiones política y militar del conflicto armado, con la que se pretende generar la aparente desconexión entre economía y política, para fragmentar y simplificar la discusión sobre dichos nexos.

El uso de casos ejemplarizantes se propone como forma de legitimación de los sistemas de valores a través de las cuales se pretenden formular las grillas semióticas que contribuyen a expandir el horizonte de sentido neoliberal: "Miren a James Rodríguez, que recibió esta mañana en España el Botín de Oro [...] ¡Miren a nuestra selección o a Falcao! ¡Miren a Catherine Ibargüen, a Nairo Quintana, a Mariana Pajón! ¡Qué ejemplo! ¡Qué 
ejemplo el que nos dan! Ellos compiten para ganar. Ellos quieren siempre más. Ellos trabajan por ser los mejores ¡Y lo logran!”. DP pretende estabilizar la individualidad, la competencia, la ambición y el éxito como valores fundamentales para la consolidación de un sistema del que no se reflexionan sus efectos de marginalización, jerarquización y segregación. La ejemplificación, de esta manera, se constituye en un recurso con el que se elabora el valor de lo heroico y se propone el sentido de sacrificio de la disciplina individual, todo lo cual se relaciona con el ideario de la competencia y la lógica del ascenso social. Si bien el marco neoliberal de la competencia y la ambición se fusionan en el concepto del héroe, dicho marco, además, integra elementos del campo semántico de la guerra: "máximo artillero", "ganar" y "disciplina" entre otros itens lexicales.

El recurso de la ejemplificación además de evocar los valores y principios de acción a través de la exaltación de los rasgos que les son atribuidos a los agentes, construye el horizonte simbólico-moral desde el que es posible interpretar el supuesto buen hacer. El sistema axiológico se formula como el mapa orientador de las posibles (inter)acciones que conducen al progreso y a la superación de las condiciones adversas que son propuestas como si obedecieran a elecciones individuales que realizan los agentes sociales. La personalización por determinación a través de la individuación (Van Leeuwen, 1996), es decir aquella en la que la identidad explícita de los actores se formula como parte del proceso argumental, se constituye en el condicionante cognitivo que, a lo largo del discurso, se re-elabora para desfocalizar el carácter social de los asuntos nucleares producidos discursivamente: la pobreza, la seguridad, la paz, la equidad, etc. Los recursos discursivos de individualización son usados como dispositivos de subjetivación y como componentes semióticos orientadores de los procesos de interpretación, que desestructuran la construcción de formas de inteligibilidad que permitirían entender las relaciones de poder desde las que se teje lo social, lo económico y lo político.

El tema de la paz se propone como un fin en si mismo, a partir de lo cual se elide la discusión sobre la justicia social, elemento que garantizaría las condiciones necesarias para que la violencia estructural no se vuelva a repetir. El ideario que subyace al concepto de paz se articula a una relacion instrumental, por causa de la cual se desligan los antecedentes sociales en razón de los cuales se han conformado los actores colectivos que hasta la fecha siguen enfrentados en los distintos esceanarios en los que se desarrolla el conflicto armado. La instrumenalización de la paz se entiende desde los requerimientos de eficiencia y de 
estabilidad jurídica y política que requiere el mercado para consolidarse y expandirse en las distintas zonas del territorio nacional, en desmedro de la formulación de la paz como derecho y como condición para el desarrollo de las capacidades individuales y colectivas en relación al buen vivir.

La estabilización de la representación de la paz como fin instrumental se articula a recursos de reiteración, generalizacion y marcadores con el propósito de activar emociones con fines de orientación interpretativa. El ensamblaje estrategico de los recursos semióticodiscursivos se orienta al reforzamiento del sentido de sacrificio y de esfuerzo que se perfila a lo largo del discurso, destacandose el lugar de agente del gobierno y del Estado en la búsqueda de la paz, y de las FARC como supuesto único agente colectivo que lleva a cabo acciones de guerra y, por consiguiente, de vulneración de derechos. La legitimación de la visión instrumental de la paz se concreta cuando en el discurso los agentes son formulados como víctimas o victimarios, y no como sujetos que se relacionan en tramas complejas en las que las violencias se llevan a cabo de diversas formas. El DP apela a la noción de víctima para conmover y para generar adesión en torno a las propuestas gubernamentles: “¿Qué familia no tiene un padre o una madre, un hermano o una hermana, un primo o un amigo que no haya sido víctima del conflicto?".

La representación de la seguridad se propone como un eje nuclear en la propuesta de gobierno y como un requisito para la reproducción del régimen de acumulación. Las fuerzas de seguridad del Estado se representan como baluartes de la democracia y de la libertad, y como "guardianes de la paz". Esta representación de las fuerzas armadas desarticula la paz de las demandas de los movimientos sociales de ampliación del acceso a la justicia, lo cual implica el juzgamiento de los agentes de seguridad del Estado que han cometido graves violaciones de derechos humanos por acción propia o en colaboración con estructuras de criminalidad paramilitares.

La inclusión del tema de la seguridad en el apartado correspondiente a la educación permite identificar argumentos desde los que se valida la intervención del Estado a través de sus fuerzas de seguridad, en todos los espacios de la vida social: "A nuestras Fuerzas Armadas [...] les digo que no podemos bajar la guardia [...] Los Colombianos necesitamos sentirnos más seguros y más protegidos [...] la seguridad ciudadana continuará siendo prioridad". Para esto, se activa el trauma colectivo asociado al conflicto histórico y a la violencia, y se legitima la securitización a través de la evocación del potencial riesgo al que 
podrían estar expuestos los agentes sociales, haciendo referencia a hechos coyunturales como forma de condicionamiento cognitivo y emocional: "Y aquí quiero hacer una advertencia: los hechos de VIOLENCIA de las últimas semanas son una contradicción inaceptable, y ponen en riesgo el mismo proceso". De esta manera, la actualización del impacto emocional y del shock que se deriva del recuerdo de la violencia son potencializados semióticamente como mecanismos de persuasión al servicio del proyecto de poder del presidente Santos.

La convocatoria de adhesión y de acción conjunta en torno a los proyectos de la administración Santos se constituye en una de las estrategias, a través de la cual el Presidente valida el modelo neoliberal sustentado en la protección de la propiedad privada, la individualización de los procesos de desigualdad desde los que se explica la pobreza, la construcción del marco de los derechos como beneficios o como inversiones, y la refrendación de la lógica de la competencia. Estos referentes se proponen como si fuesen requisitos sin los cuales no es posible el logro de los objetivos fijados en la agenda gubernamental:

Un país que cree en la propiedad privada y la protege [...] GRAN PROPÓSITO NACIONAL

[...] avanzaremos hacia nuestra gran meta de erradicar la pobreza

100 mil viviendas gratis para los más pobres [...] ¡muchas de ellas gratis!

[...] seguiremos avanzando en la búsqueda de una mejor salud [...] como ya lo hicimos con la unificación y ampliación de los planes de beneficios

[...] nuestros campesinos necesitan mejores servicios públicos, más escuelas, acueductos y alcantarillados rurales [...] por eso vamos a dedicar al agro el presupuesto de inversión más grande que jamás se haya destinado [...]

¿Qué significa ser el país más educado de América Latina? [...] significan que las mentes más brillantes compitan por estudiar vivir y trabajar en Colombia

La validación de la propiedad privada como "propósito nacional" se sustenta en la supuesta ausencia de conflicto en torno al proyecto privatizador, el cual se ha intensificado desde la década de los años 90 en Colombia. Bajo este presupuesto, la paz y la propiedad privada se sugieren como la conjunción que, apriorísticamente, conduce al progreso y a la felicidad colectiva. Esta misma lógica se profundiza cuando el DP apropia metáforas ontológicas para definir conceptualmente los efectos de la desigualdad como si fuesen 
substancias (la pobreza como cuerpo susceptible de ser erradicado) y no fenómenos sociales que obedecen a lógicas de poder enmarcadas en el acceso a los recursos socialmente producidos. En consecuencia, la ausencia de problematización de las relaciones que hay entre la validación de la propiedad privada, la intensificación de la pobreza y los procesos de concentración y acumulación de capital contribuye a desconocer las discusiones que desde distintos sectores sociales se han llevado a cabo sobre estos temas y que podrían conducir al logro de la paz y al fortalecimiento de la democracia.

La validación del modelo neoliberal también se efectúa a través de la construcción de la representación de asistencia focalizada, la cual se soporta sobre la representación de los derechos sociales como beneficios o inversiones que se formulan a discrecionalidad de las autoridades y que toman como sujeto de intervención a los sectores sociales más vulnerables. Las expresiones "viviendas gratis" y "planes de beneficios" resaltan el carácter agencial de las autoridades gubernamentales y proponen a los sujetos de intervención como pacientes, a los cuales se les otorga beneficios específicos en correspondencia con la promesa de futuro elaborada discursivamente. Desde esta perspectiva, las obligaciones internacionales del Estado colombiano en materia de garantía de los derechos sociales son disimuladas bajo la acción demagógica mediante la que el campo semántico de la economía se activa cognitivamente en las unidades léxicas "beneficio" e "inversión”. Así, se extrapola la lógica costo-beneficio de la ganancia mercantil al ámbito de los derechos, para cuya concreción se formula como criterio de plausibilidad su potencial carácter económico ligado al sentido de ganancia.

El discurso formula implicaturas y valida sobreentendidos que contribuyen a la estabilización de la matriz epistémica neoliberal como horizonte de sentido de lo posible y lo plausible, como camino y a la vez como la meta de construcción de un mundo imaginado, basado en la utopía liberal del libre mercado. El sentido de avance y de progreso adquiere valor discursivo en tanto permite identificar los centros de significación o los núcleos semántico-pragmáticos que se jerarquizan en el discurso, desde los que se define la representación de lo transicional: "La visión de COLOMBIA EN PAZ, CON EQUIDAD Y EDUCADA impulsa el crecimiento económico, con más trabajo y más bienestar para las familias colombianas [...] COLOMBIA EN PAZ, CON EQUIDAD Y EDUCADA ¡es la visión que nos cambiará para siempre!". 
El análisis de las asociaciones semánticas de la unidad 'bienestar' permite verificar la consolidación del proceso de mercantilización de los derechos y el interés de sobreponer los marcos conceptuales del campo de la economía sobre los procesos de provisión del bienestar. La unidad léxica "bienestar" solo aparece una vez y su vinculación semántica da cuenta de la formulación del sentido de beneficio, progreso y desarrollo, entre otros (ver Imagen 1). Resulta paradójico que, pese a que el DP se formule sobre la base de la promesa futura de una vida mejor para todos los colombianos, la noción de bienestar no sea el referente desde el cual se enuncian las posibles directrices de política social, para la segunda administración de Santos. Esto adquiere sentido si se tiene en cuenta que las discusiones contemporáneas sobre el bienestar incluyen, en la mayoría de los enfoques de política social — salvo en neoliberal—, las intervenciones activas del Estado para gestionar los desequilibrios inherentes al régimen de acumulación, mediante la implementación de políticas distributivas y redistributivas. Esto explica la razón por la cual la unidad léxica "distribución” no aparece en el corpus y tampoco se evidencia algún tipo de asociación entre las unidades léxicas "bienestar" y "derecho".

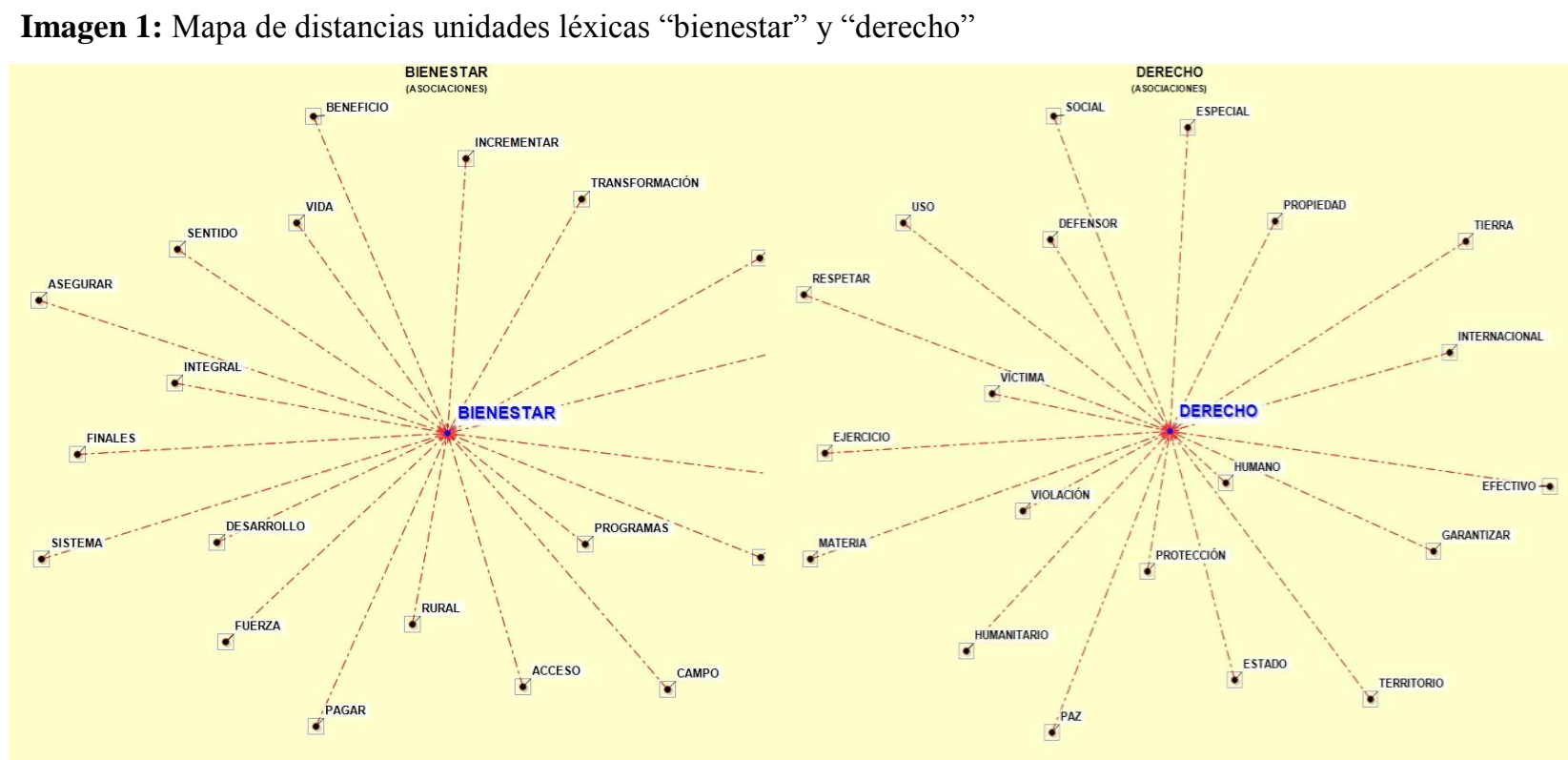

Fuente: Datos de T-Lab 7.3

La representación de los derechos se verifica en las asociaciones semánticas de la unidad léxica "derecho", de acuerdo con las cuales, por una parte, se observa proximidad con el concepto de propiedad, y, por otra, se construyen relaciones con los referentes discursivos que enmarcan el desarrollo del conflicto armado: "derecho internacional humanitario", 
"víctima", "violación de derechos", "derecho internacional", "protección”, "Estado" y "paz". El DP permite verificar la baja vinculación de la unidad léxico-semántica "derecho" con los elementos que componen la ciudadanía social como el trabajo, la salud, la educación, la vivienda, el medio ambiente, la cultura, la seguridad alimentaria y la protección social. Pese a que se verifica cercanía semántica con las unidades léxicas "tierra” y “territorio", el DP, en el eje referido a la paz, no hace referencia a las estrategias de restitución de tierras a través de las cuales es posible garantizar el retorno a sus territorios a las comunidades que han sido objeto de desplazamiento forzado por causa del conflicto armado.

La promesa de un país mejor que se formula en las unidades temáticas correspondientes a paz, equidad y educación el DP se construye en relación a valores premodernos que también contribuyen a la estabilización de la matriz epistémica neoliberal. Estos valores se representan discursivamente en articulación con referentes comunes vinculados al campo semántico de la familia y de la religión, todo lo cual profundiza el sentido de sacrificio, renuncia y heroísmo: “A mi familia [...] quiero expresarle, ante todo el país, mi profundo amor y gratitud [...]" y "pido a Dios que me ilumine y me guie en esta tarea”. Estas formas de apelación a los pilares axiológicos comunes sustentan la estrategia de legitimación sobre la base de la autoridad moral que se atribuye quien asume el canon moral aceptado socialmente. Se formula una lógica coextensiva que va del lugar institucional ocupado, pasando por el proceso de autorización moral, para llegar a la validación social de las directrices de acción propuestas.

\section{Conclusiones}

El discurso de posesión presidencial de Juan Manuel Santos, para su segundo periodo de gobierno, no solo anuncia las directrices de intervención gubernamentales, sino que, mediante el uso de distintos tipos de recursos semiótico-discursivos, formula marcos conceptuales que contribuyen a la fundamentación representacional del régimen de acumulación neoliberal. Estos marcos toman como punto de referencia la exaltación del esfuerzo y la competencia individual, la validación de la propiedad privada, la mercantilización de los derechos y la securitización de todos los ámbitos de la vida social. Así, a los tres ejes de la intervención gubernamental — “paz”, "equidad” y “educación”- les son superpuestas las lógicas que operan en el campo semántico de la economía y le son 
asignadas las representaciones bajo las cuales el DP hace coincidir el futuro imaginado del proyecto transicional, con el escenario de acción de las intervenciones neoliberales.

El proceso semiótico-discursivo de modulación y estabilización de la matriz epistémica neoliberal no solo tiene como efecto formulación del andamiaje representacional desde el cual los agentes sociales llevan a cabo acciones y disposiciones en torno a los asuntos que son referenciados. También tiene una función de subjetivación desde la que, mediante la desactivación de la capacidad agencial de los sujetos que son referenciados e interpelados en el DP, y a instancias de la sobreexposición de la capacidad de acción gubernamental, los agentes a los que se dirigen las intervenciones estatales son propuestos como si fuesen destinatarios de un conjunto de políticas públicas que apriorísticamente conllevarían el mejoramiento del bien estar general. En este sentido, los sujetos políticos son minimizados en su capacidad de participación efectiva en la definición de los asuntos públicos y solo son reconocidos en tanto sus potenciales acciones puedan ser interpretadas como funcionales y afines al proyecto gubernamental formulado y legitimado.

La funcionalización de los distintos sujetos políticos que son interpelados a través del DP pasa por el uso de marcadores de activación emocional, algunos de los cuales suponen la evocación de un pasado violento común, en el que no se reconoce la participación de las fuerzas de seguridad del Estado ni de actores legales e ilegales de la extrema derecha. Los mecanismos de evocación del pasado violento fusionan la actualización cognitiva de las vulneraciones de las que han sido objeto quienes han sido victimizados en el marco del conflicto armado, con la sugerencia de un potencial riesgo a la seguridad y la vida para el cual todos deben estar preparados y por lo cual todos los ciudadanos deben validar el fortalecimiento de las fuerzas de seguridad estatales. El resultado de este proceso es la dislocación de la capacidad crítica de los agentes que son interpelados a través del DP y el condicionamiento para que lleven a cabo la aceptación tácita de la agenda neoliberal que el presidente y su equipo de gobierno proponen como programa orientado al logro de un supuesto futuro mejor.

Recebido em: fevereiro de 2016 Aprovado em: maio de 2016 


\section{Referencias bibliográficas}

BAUMAN, Zygmunt (2009) Modernidad líquida. Buenos Aires: Fondo de Cultura Económica.

BOURDIEU, Pierre (2012) La distinción. Criterio y bases sociales del gusto. Buenos Aires: Taurus.

CORREDOR, Consuelo (1992) Los límites de la modernización. Bogotá: Universidad Nacional de Colombia - Centro de Investigación y Educación Popular (CINEP).

DELEUZE, Gilles y GUATTARI, Félix (2013) El antiedipo. Capitalismo y esquizofrenia. Buenos Aires: Paidós.

DELEUZE, Gilles y GUATTARI, Félix (2012) Mil mesetas. Capitalismo y esquizofrenia. Valencia: Pre-Textos.

GUATTARI, Félix (2013) ¿Dónde comienzan y dónde terminan los equipamientos colectivos? En: Líneas de fuga. Por otro mundo de posibles. Buenos Aires: Editorial Cactus.

FABBRI, Paolo y MARCARINO, Aurelia (2011) La comunicación política. Transformaciones del espacio público. En: DeSignis. No. 2. Barcelona: Gedisa.

FOUCAULT, Michel. (2012). Nacimiento de la biopolítica. Buenos Aires: Fondo de Cultura Económica.

FRIEDMAN, Milton (2008) Capitalismo y libertad. Ensayos de política monetaria. Madrid: Síntesis.

KLEIN, Naomi (2011) La doctrina del Shock. El auge del capitalismo del desastre. Buenos Aires: Paidós.

LEAL, Francisco y DÁVILA, Andrés (2010) Clientelismo: el sistema político y su expresión regional. Bogotá: Universidad de los Andes.

LEGHISSA, Giovanni (2012) Neoliberalismo. Un'introduzione critica. Roma: Mimesis.

LIBREROS, Daniel y CARRERO, Diego (2014) Financiarización, crecimiento inestable y vulnerabilidad económica en América Latina y en Colombia 1990-2013. En: América Latina en medio de la crisis mundial. Trayectorias nacionales y tendencias regionales. Buenos Aires: Consejo Latinoamericano de Ciencias Sociales.

LOPEZ, Claudia (editora) (2010) Y refundaron la patria... de cómo mafiosos y políticos reconfiguraron el Estado colombiano. Bogotá: Random House Mondadori.

MÚNERA, Leopoldo y RODRÍGUEZ, Nathaly (2009) Fragmentos de lo público-político. Colombia siglo XIX. Medellín: La Carreta Histórica - Universidad Nacional de Colombia. 
PARDO ABRIL, Neyla (2014) Discurso en la Web. Pobreza en YouTube. Bogotá: Universidad Nacional de Colombia.

PARDO RUEDA, Rafael (2010) La historia de las guerras. Bogotá: Zeta Histórica.

ROMERO, Mauricio (editor) (2011) La economía de los paramilitares. Redes de corrupción, negocios y política. Bogotá: Random House Mondadori. 